DOI: $10.15690 /$ vramn637

М.А. Сновская ${ }^{1}$, Л.С. Намазова-Баранова ${ }^{1,2,3}$, Е.Л. Семикина ${ }^{1}$, С.Г. Макарова ${ }^{1,2}$, О.В. Кожевникова ${ }^{1}$, А.С. Батырова ${ }^{1}$, А.А. Марушина ${ }^{1}$

${ }^{1}$ Научный центр здоровья детей, Москва, Российская Федерация

2 Первый Московский государственный медицинский университет им. И.М. Сеченова,

Москва, Российская Федерация

${ }^{3}$ Российский национальный исследовательский медицинский университет им. Н.И. Пирогова,

Москва, Российская Федерация

\title{
Возрастная эпидемиология
}

\section{распространенности антительного ответа у детей с пищевой аллергией}

Пищевая аллергия (ПА) - важная проблема здравоохранения, значительно ухудшающая качество жизни пациента и членов его семьи. ПА у детей наиболее часто обусловлена белками яйца, молока, сои, пшеницы и орехов, однако любой пищевой продукт может потенциально вызвать аллергическую реакцию. В связи с этим цель исследования - изучить возрастную динамику антительного ответа и выбрать наиболее значимые триггеры образования специфических IgE у детей с ПА. Материалы и методы. В исследование включены 682 ребенка с ПА, разделенные на группы в соответствии с возрастом: 2-5 месяцев, 6-18месяцев, 1,5-4 года, 4-10лет, старше 10лет. Пациентам определен уровень IgE к аллергенам злаков, овощей, банана, мяса и птицы. Результаты. Выявлена возрастная динамика числа IgE-положительных ответов. Для детей 2-5 месяцев наиболее значимыми триггерами образования IgЕ являлись картофель, свинина и злаки (8-14\%). Высокая частота позитивных ответов наблюдалась у более старших детей. Наиболее значимыми триггерами образования IgE для детей 6-18 месяцев являлись аллергены картофеля (22,7\%), гречки (19,3\%), злаков (10-15\%), для детей 1,5-4 лет - аллергены банана (29,5\%), злаков, моркови и картофеля (19,5-24\%), для детей 4-10 лет - аллергены банана, моркови и злаков (20-28\%), для детей старше 10 лет - аллергены моркови (47,5\%), банана, злаков и томатов (30-36\%). Среди всех детей, включенных в исследование, число пациентов с позитивным ответом на курицу было минимальным, а ІgЕ к животным аллергенам встречались у 8-15\% из них. Заключение. У детей разных возрастных периодов сенсибилизация обусловлена различными аллергенами, она расширяется по мере взросления, при этом спектр пищевых продуктов с низкой аллергенной активностью остается для пациентов постоянным. Возрастные особенности антительного ответа требуют дифференцированного подхода в диагностике.

Ключевые слова: пищевая аллергия, атопический дерматит, пищевые аллергены, диагностика.

(Для цитирования: Сновская М.А., Намазова-Баранова Л.С., Семикина Е.Л., Макарова С.Г., Кожевникова О.В., Батырова А.С., Марушина А.А. Возрастная эпидемиология распространенности антительного ответа у детей с пищевой аллергией. Вестник РАMH. 2016;71(1):68-76. doi: 10.15690/vramn637)

M.A. Snovskaya ${ }^{1}$, L.S. Namazova-Baranova ${ }^{1,2,3}$, E.L. Semikina ${ }^{1}$, S.G. Makarova ${ }^{1,2}$, O.V. Kozhevnikova ${ }^{1}$, A.S. Batyrova ${ }^{1}$, A.A. Marushina ${ }^{1}$

${ }^{1}$ Scientific Center of Children's Health, Moscow, Russian Federation

2 I.M. Sechenov First Moscow State Medical University, Moscow, Russian Federation

${ }^{3}$ N.I. Pirogov Russian National Research Medical University, Moscow, Russian Federation

\section{Age-specific Epidemiology of the Antibody Response Prevalence in Children with Food Allergy}

Food allergy (FA) is an important health problem which determines lower life quality of a patient and his family. Egg proteins, milk, soy, wheat, and nuts provoke FA more often but any food product may potentially cause allergic reactions. So the aim was to study the age-specific dynamics of antibody response and select the most meaningful IgE production triggers in children with PA. Materials and Methods. The study included 682 children with FA divided into groups according to age: 2-5 months, 6-18 months, $1.5-4$ years, 4-10 years, older than 10 years. The IgE levels to cereals, vegetables, bananas, meat, and poultry allergens were measured in blood samples. Results. The age dynamic of IgE-positive responses was detected. The frequency of positive responses was higher in older children. The most significant IgE production triggers for 2-5 months children were allergens of potatoes, pork and cereals (8-14\%); for 6-18 month children - potatoes (22.7\%), buckwheat (19,3\%), cereals (10-15\%); for 1.5-4 years children - bananas (29.5\%), cereals, carrots and potatoes (19,5-24\%); for 4-10years children - bananas, carrots and cereals (20-28\%); for the senior children - carrots (47.5\%), bananas, cereals and tomatoes (30-36\%). Chicken-specific IgE-positive response was minimal for all ages, and meat or poultry specific IgE were observed in $8-15 \%$ of patients. Conclusion. Different groups of food allergens provoke sensitization in children during their life. The range of food products with low allergenic activity remains constant in various ages. Age characteristics of IgE production requires differentiated diagnosis approach.

Key words: food allergy, atopic dermatitis, food allergens, diagnostic.

(For citation: Snovskaya MA, Namazova-Baranova LS, Semikina EL, Makarova SG, Kozhevnikova OV, Batyrova AS, Marushina AA. Age Epidemiology of the Antibodies Answers Prevalence in Children with Food Allergy. Annals of the Russian Academy of Medical Sciences. 2016;71(1):68-76. doi: 10.15690/vramn637) 


\section{Обоснование}

Пищевая аллергия (ПА) - это патологическая реакция организма, развивающаяся в ответ на прием пищевого продукта. В ее основе лежат специфические IgEопосредованные иммунологические реакции, клеточный иммунный ответ (не-IgE-опосредованные) или их сочетание [1]. Пищевая аллергия весьма распространена, особенно среди детей: ребенок с рождения сталкивается с огромным числом пищевых аллергенов, количество которых для него увеличивается по мере взросления.

Диагностика ПА основана на анализе данных аллергологического анамнеза, клинической картины заболевания, результатов специфического аллергологического обследования, а также на положительном эффекте от элиминационной диеты и результатах провокационной пробы [2]. Важным методом диагностики IgE-опосредованной пищевой аллергии является in vitro-тестирование, наиболее актуальное при отсутствии четкого указания на причинно-значимый фактор, при множественной пищевой аллергии, невозможности применения элиминационной диеты или ее ограниченной функциональности, а также при развитии перекрестных аллергических реакций.

Согласно данным многолетнего исследования, посвященного изучению механизма развития аллергии (Mechanisms of the Development of Allergy, MeDALL), c возрастом расширяется спектр сенсибилизации, в развитие аллергических реакций вовлекается все большее число аллергенов, при этом латентная сенсибилизация организма (наличие в сыворотке аллергенспецифических IgE при отсутствии клинических симптомов) во многих случаях предшествует развитию аллергической болезни в последующем [3, 4]. Частота выявления IgE к аллергенам молока, яйца, сои, арахиса, пшеницы достаточно хорошо изучена. Как показывают многочисленные исследования, пищевая аллергия у детей наиболее часто обусловлена именно белками этих продуктов [5]. R.J. Rona и соавт. провели метаанализ 51 публикации, согласно которым распространенность ПА к пищевым продуктам у детей составляла от 1,2 до $17 \%$ для молока, от 0,2 до 7\% для яиц, 0-2\% для арахиса и рыбы [6]. В Великобритании когортное исследование по распространенности ПА у детей раннего возраста продемонстрировало наличие клинических симптомов у 7-14\% обследованных детей в возрасте 3,6 и 12 мес в ответ на продукты, содержащие аллергены молока, яйца, рыбы, арахиса, кунжутного семени, пшеницы [7]. По данным исследований, проведенных в НЦЗД, частота клинических реакций на молочные продукты у детей с ПА с возрастом уменьшалась и составляла $15,4 \%$ у пациентов в возрасте 10-17 лет, при этом специфические $\operatorname{IgE~к~белкам~коровьего~молока~определялись~у~64,8\% ~}$ больных этой возрастной группы [2]. В то же время, как по данным анамнеза, так и по результатам определения специфических IgE, с возрастом увеличивалась и частота сенсибилизации, и частота аллергических реакций на овощи и фрукты, рыбу, морепродукты [2]. По данным О.Б. Сосниной и соавт., развитие ПА связано с сенсибилизацией к продуктам растительного, животного происхождения, а также с сочетанной сенсибилизацией, соответственно, у 40, 11 и 49\% подростков [8]. В работе И.И. Балаболкина в качестве триггеров аллергических реакций указываются шоколад, какао, цитрусовые, клубника, земляника, мед, мясо птиц и животных, а также пищевые злаки [9]. В то же время частота выявления у детей с ПА аллергенспецифических IgE ко многим общеупотребительным пищевым продуктам, каждый из которых может быть аллергеном (злаки, овощи, различные виды мяса), изучена недостаточно.

Цель исследования - изучить возрастную динамику уровня аллергенспецифических IgE у детей с пищевой аллергией и выбрать наиболее значимые триггеры образования IgE.

\section{Методы}

\section{Дизайн исследования}

Проведено сравнительное ретроспективное исследование возрастной динамики IgE-позитивного ответа у детей с пищевой аллергией к аллергенам злаков (пшеница, рожь, овес, ячмень, кукуруза, рис, гречка), овощей (картофель, морковь, капуста, брокколи, тыква, свекла, томаты), банана, мяса животных и домашней птицы (говядина, свинина, кролик, баранина, курица, индейка).

\section{Критерии соответствия}

Критерии включения в исследование: дети в возрасте от 2 мес до 17 лет включительно (304 девочки, 378 мальчиков) с клиническими симптомами аллергии (атопический дерматит вне зависимости от степени тяжести и/или гастроинтестинальные симптомы), возникающими при употреблении пищевых продуктов. Законные представители пациентов были проинформированы о процедурах и плане исследования и дали письменное согласие на участие в нем, а также обработку и публикацию полученных результатов.

\section{Условия проведения}

Исследование выполнено на базе ФГАУ «Научный центр здоровья детей» Министерства здравоохранения Российской Федерации (ФГАУ «НЦЗД» Минздрава России). Прием пациентов осуществлялся в консультативнодиагностическом центре, в отделении питания здорового и больного ребенка. Серологическое тестирование образцов крови пациентов проводилось в отделе инструментальной диагностики.

\section{Продолжительность исследования}

Общая продолжительность исследования составила 11 месяцев. Обследование пациентов и однократное взятие образцов крови для серологического тестирования проводились с января по декабрь 2015 г.

\section{Описание медицинкого вмешательства}

С целью проведения аллергологического обследования, назначенного пациенту при первичном обращении, была взята венозная кровь из локтевой или подкожной вены запястья с помощью системы однократного применения BD Vacutainer Safety-Lok (Becton Dickinson and Company, США) в количестве 3-5 мл. Для сбора и хранения образцов крови применялись пробирки с активатором свертывания и разделительным гелем (BD Vacutainer). Собранные образцы центрифугировалась в течение 10 мин при 2 тыс. оборотов и хранилась при температуре от +4 до $+8{ }^{\circ} \mathrm{C}$ в течение 2 сут до проведения серологического тестирования.

\section{Исходы исследования}

Наличие IgE-позитивных ответов при тестировании с аллергенами сыворотки пациентов констатировали в тех случаях, когда концентрация аллергенспецифических IgE была равна или превышала значение 0,35 кЕ/л. 


\section{Методы регистрации исходов}

Содержание аллерген-специфических IgE к пищевым аллергенам (злаков, овощей, банана, мяса животных и домашней птицы) определяли с помощью непрямого иммунофлуоресцентного метода на автоматическом анализаторе ImmunoCAP250 (компания-производитель Thermo Fisher Scientific, ранеe Phadia AB, США). Граница 0,35 кЕ/л установлена точкой отсечения (cut off point) компанией-производителем диагностической тест-системы: тест считался положительным при уровне $\operatorname{IgE} \geqslant 0,35$ кЕ/л.

\section{Этическая экспертиза}

Исследование проведено в рамках научно-исследовательских работ и с информированного согласия законных представителей пациентов. Пациенты проходили плановое обследование и лечение в отделениях ФГАУ «НЦЗД» Минздрава России; взятие крови осуществлялось для выполнения исследований, назначенных врачами аллергологом или диетологом, а оставшаяся часть образца использовалась в научных целях с письменного разрешения законных представителей пациента.

\section{Статистический анализ}

Полученные данные статистически обработаны с помощью пакета программ Statistica v. 8.0 (StatSoft Inc., США) и Excel (Microsoft, США). Статистический анализ проводили при помощи непараметрических тестов в связи с распределением показателей, отличных от нормальных. Для определения значимости различий между выборками применяли критерий знаковых рангов Вилкоксона (Wilcoxon). Различия считались статистически значимыми при $p<0,01$.

\section{Результаты}

\section{Участники исследования}

В исследование включены 682 ребенка в возрасте от 2 мес до 17 лет (304 девочки, 378 мальчиков) с пищевой аллергией, проявляющейся кожными (атопический дерматит вне зависимости от тяжести - 88,43\%), гастроинтестинальными (срыгивания, тошнота, диарея, вздутие живота - 3,95\%), кожными и гастроинтестинальными (7,62\%) симптомами. Все дети были разделены на группы в соответствии с возрастом: 2-5 мес (дети на грудном вскармливании до введения прикорма, $\mathrm{n}=85), 6-18$ мес (дети, получающие прикорм, $\mathrm{n}=176), 1,5-4$ года $(\mathrm{n}=190)$, 4-10 лет $(n=151), 10-17$ лет $(n=80)$.

\section{Основные результаты исследования}

При анализе возрастных особенностей образования аллергенспецифических $\operatorname{IgE}$ были отмечены тенденция к увеличению числа пациентов, имеющих позитивный ответ на один или несколько аллергенов, вошедших в исследование, а также увеличение частоты сочетанного выявления аллергенспецифических $\operatorname{IgE}$ с увеличением возраста пациентов (рис. 1).

Выявлено статистически значимое различие числа $\operatorname{IgE-позитивных~пациентов~в~группах~детей~в~возрасте~}$ 2-5 и 6-18 мес, 6-18 мес и 1,5-4 лет, а также 4-10 и старше 10 лет (уровень значимости для всех сравниваемых групп составил $p<0,001)$. В то же время количество детей в группах 1,5-4 и 4-10 лет, имевших позитивный ответ при тестировании, статистически значимо не отличалось $(p>0,05)$.

Рассматривая антительный ответ пациентов различного возраста на каждую группу аллергенов (злаки, животные аллергены, овощи), была отмечена тенденция к увеличению с возрастом числа пациентов с пищевой аллергией, имеющих диагностически значимые уровни аллергенспецифических $\operatorname{IgE}$ (рис. 2-4).

Выявлена возрастная динамика увеличения числа пациентов c IgE-позитивным ответом при тестировании на аллергены злаков, за исключением аллергенов ячменя [коэффициент корреляции Пирсона (r) 0,89-0,99; $p<0,001]$.

Сходная динамика была показана для аллергенов овощей.

В отношении большинства аллергенов овощей было показано увеличение числа IgE-позитивных ответов в группах пациентов старшего возраста по сравнению с предыдущим возрастным диапазоном. В то же время отсутствовала динамика изменения числа пациентов, имеющих диагностически значимые уровни IgE к аллергенам картофеля, свеклы, капусты для групп детей старше 4 лет. Отмечена статистически значимая сильная взаимосвязь увеличения частоты IgE-позитивных ответов пациентов на аллергены банана, моркови, томатов ( $\mathrm{r}=0,95-0,98$; $p<0,001)$, а также тыквы, свеклы, капусты, брокколи $(\mathrm{r}=0,91-0,99 ; p<0,001)$ в зависимости от возраста.

Антительный ответ на пищевые аллергены животного происхождения отличался большим расхождением.

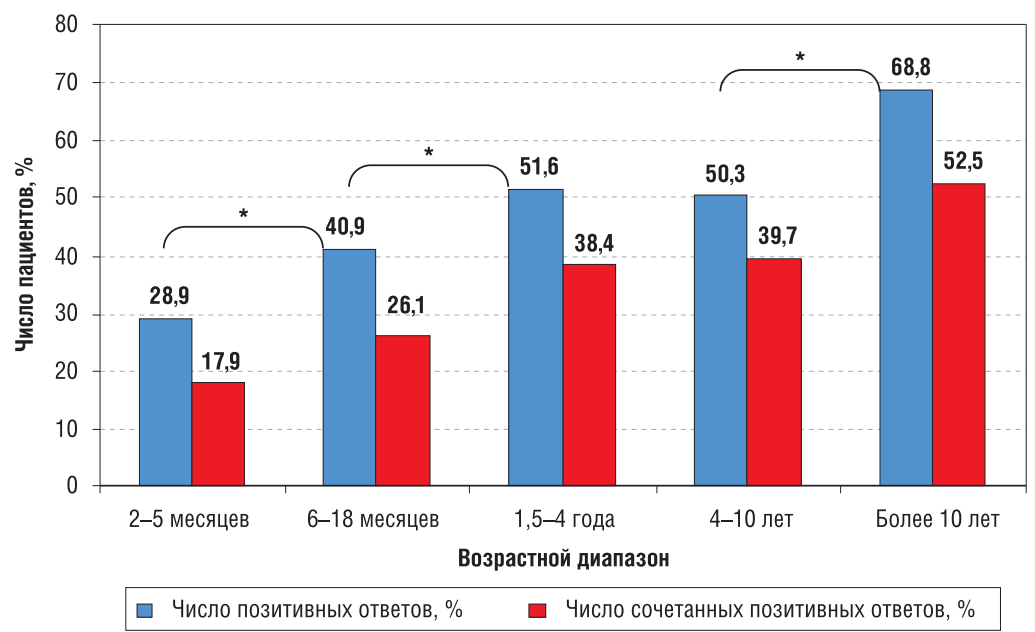

Рис. 1. Частота IgE-позитивных ответов для всех исследуемых антигенов суммарно в зависимости от возраста пациентов Примечание. * - наличие статистически значимого различия в числе IgE-позитивных ответов между смежными возрастными группами; $p<0,001$. 


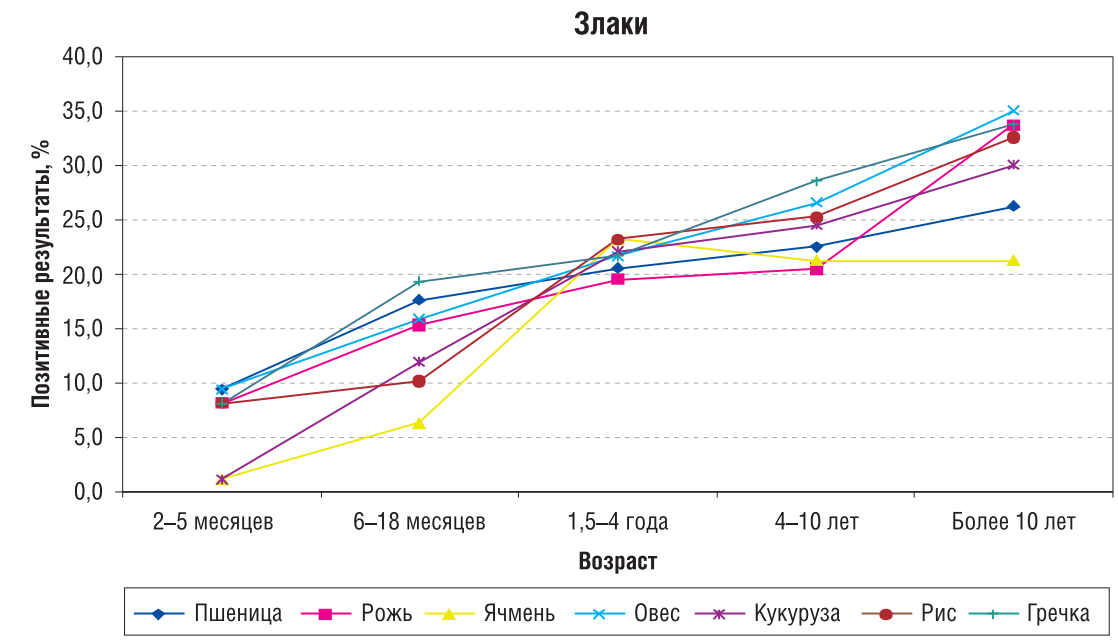

Рис. 2. Динамика изменения числа позитивных ответов при тестировании пациентов с пищевыми аллергенами злаков в зависимости от возраста пациентов

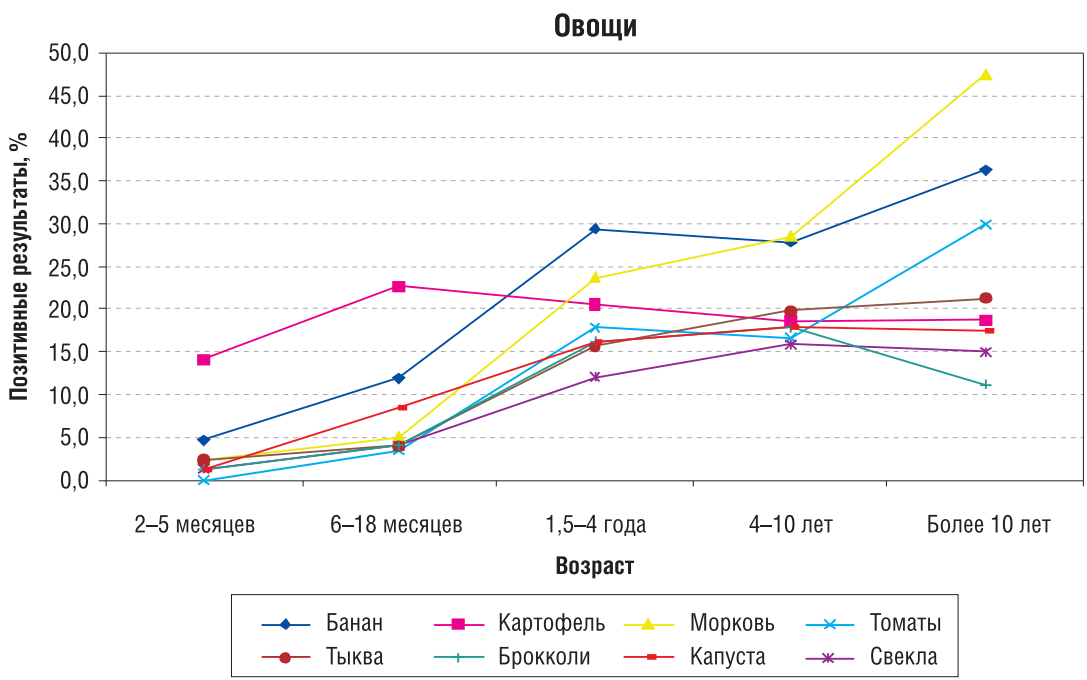

Рис. 3. Динамика изменения числа позитивных ответов при тестировании пациентов с пищевыми аллергенами овощей и банана в зависимости от возраста пациентов

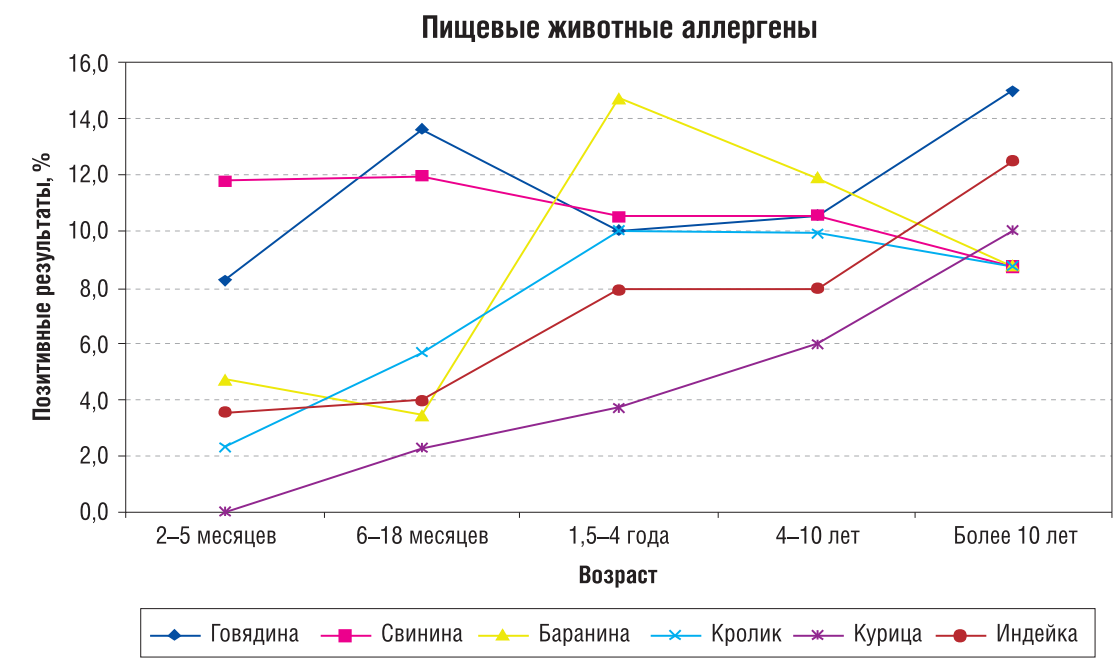

Рис. 4. Динамика изменения числа позитивных ответов при тестировании пациентов с пищевыми животными аллергенами в зависимости от возраста пациентов

В зависимости от возраста пациентов наблюдался разнородный ответ на пищевые аллергены животного происхождения: возрастало число позитивных ответов на аллергены говядины, индейки, курицы, в то же время уменьшалось число позитивных ответов на аллергены свинины. Антитела к аллергенам баранины наиболее часто выявлялись у пациентов 1,5-4 лет. Динамика изменения числа пациентов, имеющих диагностически-значимые уровни $\operatorname{IgE}$ к аллергенам свинины, кролика, говядины, индейки, между группами детей 1,5-4 и 4-10 лет отсутствовала. Отмечена статистически значимая сильная взаимосвязь увеличения частоты 


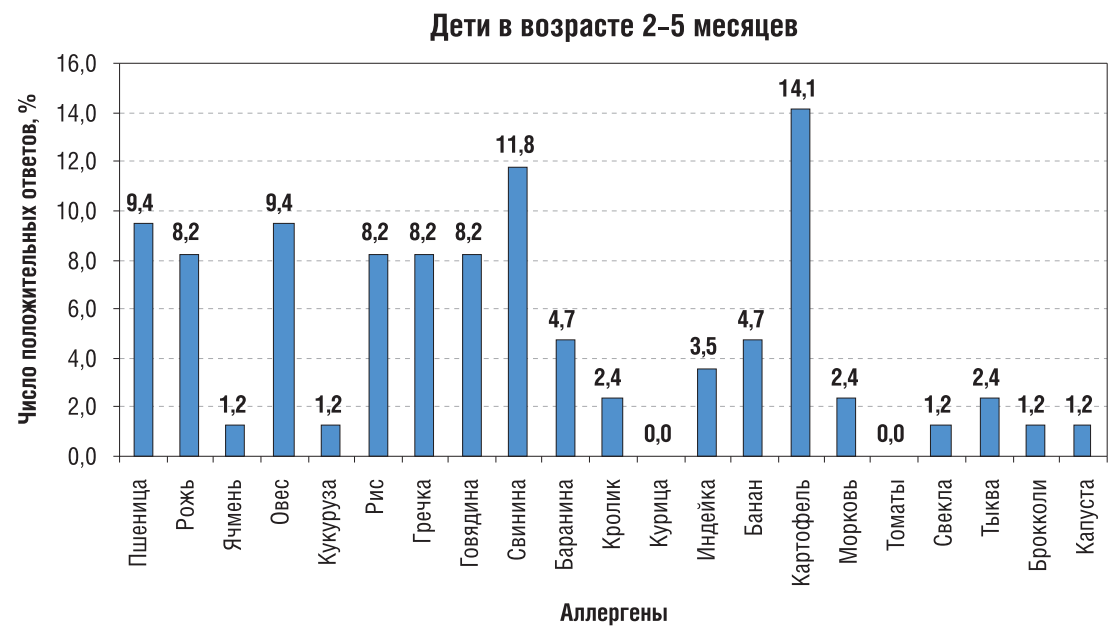

Рис. 5. Результаты выявления аллергенспецифических IgE к пищевым продуктам у пациентов первого полугодия жизни

$\operatorname{IgE-позитивных~ответов~пациентов~на~аллергены~кури-~}$ цы, индейки, кролика $(\mathrm{r}=0,90-0,96 ; p<0,001)$ в зависимости от возраста пациентов.

У детей возрастной группы 2-5 мес положительный результат верификации $\operatorname{IgE}$ к изучаемым аллергенам был получен в 28,2\% случаев, при этом сочетанные позитивные ответы встречались у 17,9\% детей. В этой группе наиболее часто выявлялись $\operatorname{IgE~к~аллергенам~}$ свинины и картофеля (11,8 и $14,1 \%$, соответственно), реже - к антигенам говядины и злаков $(8,2-9,4 \%)$. Позитивный ответ при тестировании с прочими мясными продуктами (за исключением курицы), а также бананом и овощами (за исключением томатов) встречалась у $1,2-4,7 \%$ пациентов. IgE к курице и томатам отсутствовали (рис. 5).

У детей с пищевой аллергией, которые начали получать прикорм (возрастная группа 6-18 мес), IgE к исследуемым аллергенам встречались в $40,9 \%$ случаев, при этом сочетанные позитивные ответы при тестировании были выявлены у 26,1\%. Положительный ответ при тестировании с аллергеном картофеля и гречки встречался в максимальном числе случаев - 22,7 и 19,3\%, соответственно. В $17,6 \%$ случаев позитивный результат тестирования обнаружен на аллергены пшеницы. $\operatorname{IgE~к~аллергенам~ржи,~овса~и~говядины~встречались~у~}$ 13,6-15,9\% пациентов, у 10-12\% детей - к аллергенам риса, кукурузы, свинины и банана. Число пациентов, имеющих $\operatorname{IgE}$ к прочим изучаемым аллергенам, значимо возросло и составило $3,4-8,5 \%$. Число пациентов с по- зитивным ответом на аллергены курицы осталось минимальным $-2,3 \%$ (рис. 6 ).

У 51,6\% пациентов в возрасте 1,5-4 лет были выявлены IgE к одному или нескольким исследуемым аллергенам (сочетанное выявление аллергенспецифических $\operatorname{IgE}$ наблюдалось у $38,4 \%)$. Наиболее значимыми триггерами образования $\operatorname{IgE}$ являлись аллергены банана $(29,5 \%$ детей имели позитивный ответ при тестировании), а также злаков, моркови, картофеля (19,5-24\%). IgE к другим овощам (за исключением свеклы) встречались у 15,8-18\% детей. Из животных аллергенов наибольшее число позитивных ответов встречалось на аллергены баранины - $14,7 \%$, а частота выявления $\operatorname{IgE}$ к прочим мясным аллергенам составила 8-10,5\% (за исключением курицы). Сходная частота отмечена для аллергенов свеклы (12,1\%). Наименьшее число позитивных ответов встречалось на аллергены курицы - 3,7\% (рис. 7).

У детей в возрасте 4-10 лет, имеющих пищевую аллергию, IgE к изучаемым пищевым аллергенам были обнаружены в 50,3\% случаев. При этом сочетанное выявление $\operatorname{IgE~к~нескольким~аллергенам~встречалось~}$ в $39,7 \%$ случаев. Наиболее значимыми триггерами образования IgE были банан $(27,8 \%)$, морковь и гречка $(28,5 \%)$. Антитела к аллергенам иных злаков встречались у 20-26,5\% пациентов, у 16-20\% имелись IgE к аллергенам овощей, a $\operatorname{IgE~к~животным~аллергенам~}$ выявлялись в 6-12\% случаев, при этом на аллергены курицы выявлялось наименьшее число позитивных ответов $-6 \%$ (рис. 8 ).

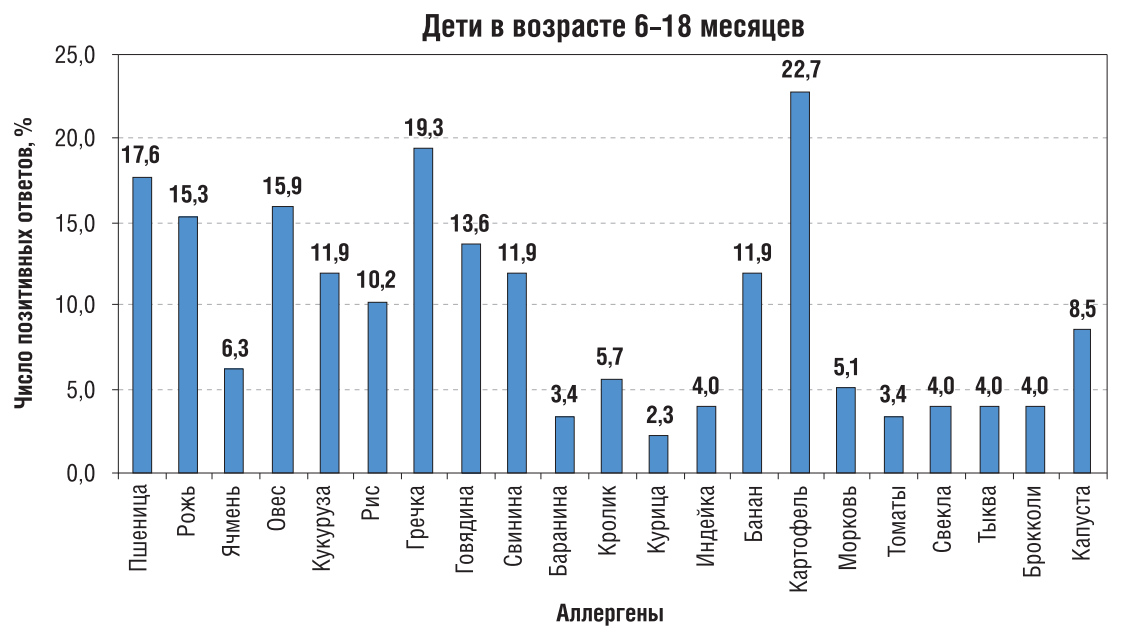

Рис. 6. Результаты выявления аллергенспецифических IgE к пищевым продуктам у пациентов в возрасте 6-18 мес 


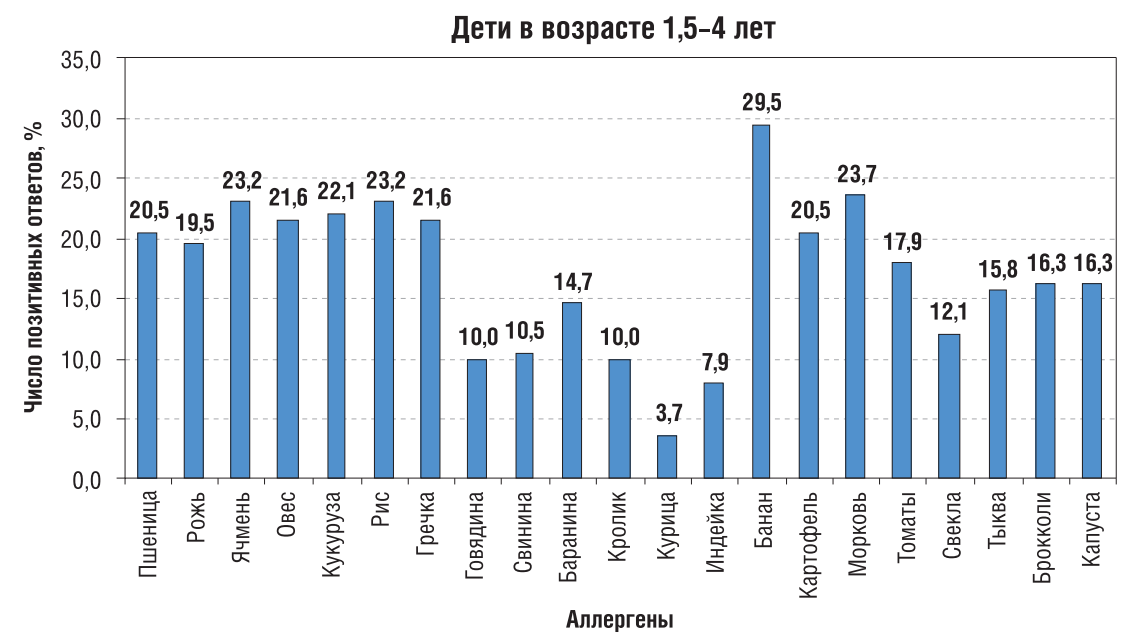

Рис. 7. Результаты выявления аллергенспецифических IgE к пищевым продуктам у пациентов в возрасте 1,5-4 лет

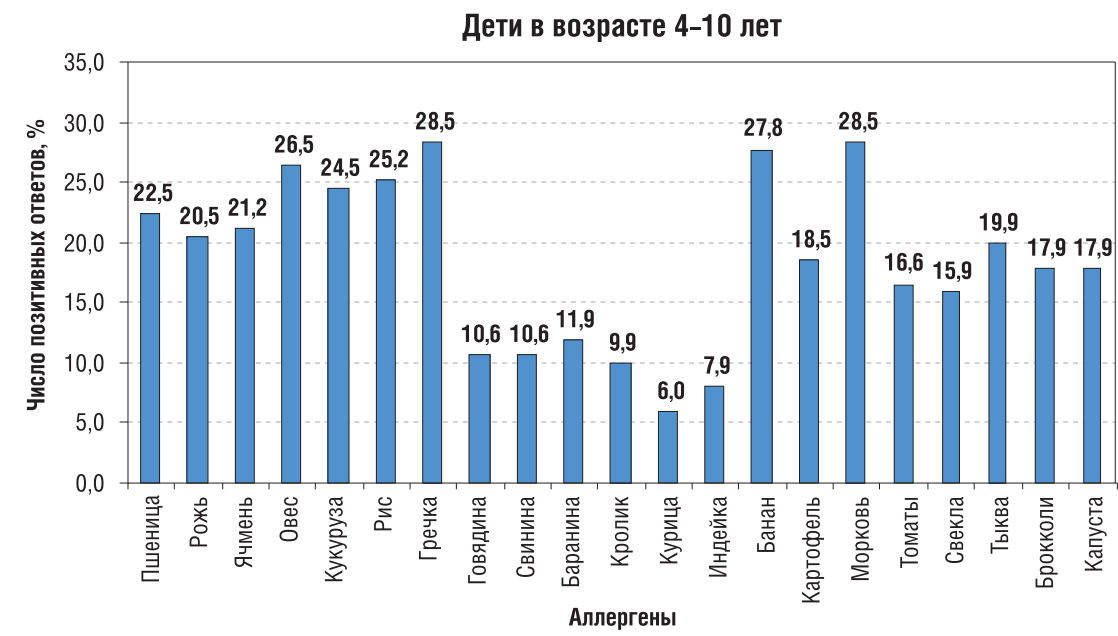

Рис. 8. Результаты выявления аллергенспецифических IgE к пищевым продуктам у пациентов в возрасте 4-10 лет

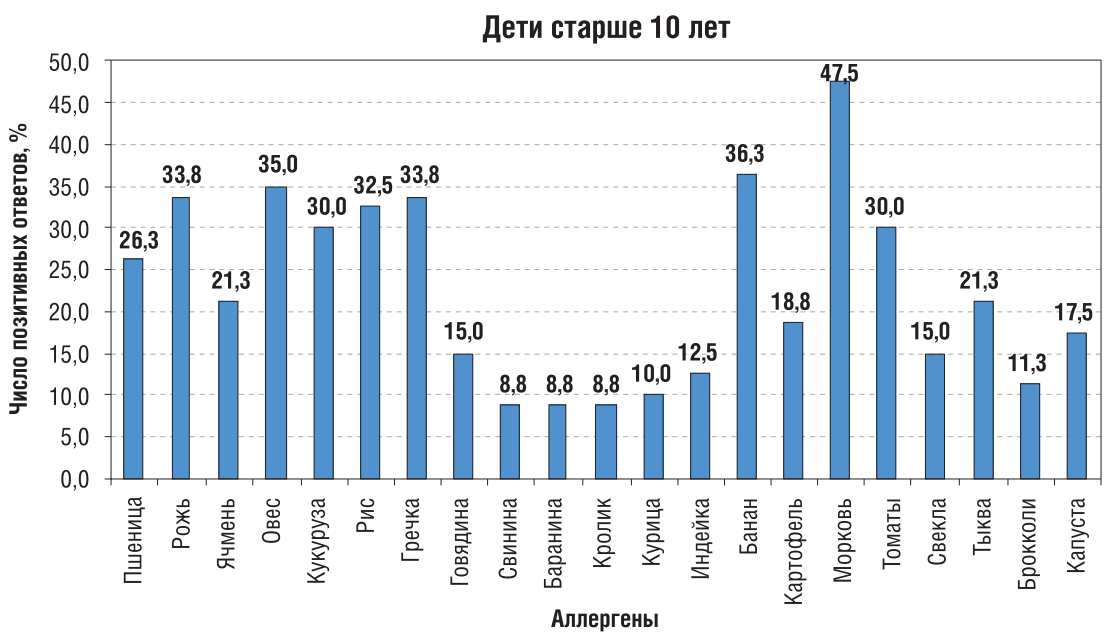

Рис. 9. Результаты выявления аллергенспецифических $\operatorname{IgE~к~пищевым~продуктам~у~пациентов~в~возрасте~старше~} 10$ лет

Анализ результатов in vitro-тестирования пациентов с пищевой аллергией старше 10 лет показал, что $68,8 \%$ из них имели IgE к исследуемым в работе аллергенам, а их сочетанное появление отмечалось у $52,5 \%$ детей. Наибольшее число позитивных ответов было обусловлено аллергенами моркови - 47,5\%. IgE к аллергенам злаков (за исключением ячменя и пшеницы), банана, томатов обнаружены у $30-36,3 \%$ пациентов. У
21,3-26\% детей выявлены антитела к ячменю, пшенице, тыкве. Число пациентов, демонстрирующих позитивный ответ на аллергены картофеля, капусты, свеклы, говядины, значимо не изменилось (15-18,8\%) по сравнению с детьми в возрасте 4-10 лет. Наименьшая частота позитивного ответа наблюдалась в отношении прочих животных аллергенов, а также брокколи 8-12,5\% (рис. 9). 


\section{Обсуждение}

Проведенное исследование показало, что IgE ко многим пищевым аллергенам, не входящим в число наиболее распространенных, появляются уже у детей первого полугодия жизни, не получающих прикорм. Ряд авторов объясняет данное явление возможностью сенсибилизации организма ребенка при контакте с аллергеном, поступавшим во время внутриутробного развития через плаценту, или контакт грудного ребенка с аллергеном через молоко матери. Также не исключается случайный контакт с аллергеном (непреднамеренное потребление еды) или даже через ингаляцию аллергена [10-12].

В ходе исследования было отмечено, что у детей с пищевой аллергией имеется возрастная динамика частоты IgE-позитивных ответов в целом, а также увеличение числа сочетанных положительных ответов. Полученные данные согласуются с результатами длительных проспективных исследований, показавших расширение спектра сенсибилизации с возрастом и значимость латентной сенсибилизации $[2,4]$.

Для детей первого полугодия жизни, имеющих пищевую аллергию, в качестве сенсибилизирующих агентов и триггеров образования $\mathrm{IgE}$ наиболее значимыми, из рассмотренных в данной работе, являлись картофель, свинина и злаки (за исключением ячменя и кукурузы). Для детей 7-18 мес наиболее значимы были аллергены картофеля и гречки, несколько меньше - аллергены злаков, за исключением ячменя и риса. Для детей 1,5-4 лет главными триггерами образования аллергенспецифических IgE являлись аллергены банана, злаков, моркови и картофеля. У детей 4-10 лет сохранялась та же тенденция: наиболее часто выявлялись антитела к аллергенам банана, злаков и моркови. При этом возрастало число позитивных результатов тестирования в целом по группе. Для детей старше 10 лет помимо аллергенов моркови, банана, злаков важным сенсибилизирующим агентом были аллергены томатов.

Таким образом, в исследовании показано, что аллергены картофеля являются значимыми для 15-22\% детей в возрасте от 2 мес до 4 лет, имеющих пищевую аллергию. При этом наши данные отличаются от результатов, полученных в 2003 г. в Италии. Так, по данным исследования B. Caruso, специфические $\operatorname{IgE}$ к аллергенам картофеля встречаются у 4,2\% детей в возрасте 0-2 лет, $11,9 \%$ детей в возрасте 3-12 лет и 10,5\% детей старше 12 лет [13]. Вместе с тем результаты определения IgE к аллергенам картофеля, полученные нами, согласуются с данными европейского исследования, основанного на анкетировании пациентов 17 больниц в 15 европейских городах, которое показало, что картофель как причина симптомов пищевой аллергии затрагивает в среднем $18 \%$ пациентов [14]. Таким образом, полученные данные говорят о важности включения в диагностическую панель in vitroтестирования аллергенов картофеля.

Появление у наших пациентов уже в первом полугодии жизни сочетанной сенсибилизации к аллергенам злаков, сохраняющейся на протяжении последующей жизни, потребовало проведения глубокого анализа структуры сенсибилизации и анализа самих аллергенов. Показанная в работе E. Varjonen ассоциация между положительным результатом орального провокационного теста и реактивностью кожи при тестировании с глиадином обозначила важность пшеницы как причинно-значимого фактора развития аллергии [15].

Известно, что пшеница, как и другие продукты, содержит множество белков - альбумины (растворимые в воде, неродственные альбуминам молока или яйца), глобулины (нерастворимые в воде), глютены, включающие в себя глиадин и глютен - главные белки пшеницы $[16,17]$. Глиадин - белок, принадлежащий к классу проламинов, составляет $28-42 \%$, а глютен $-42-62,5 \%$ всех белков пшеницы. Проламины присутствуют во всех злаках - глиадин (пшеница), секалин (рожь), гордеин (ячмень), зеин (кукуруза), авенин (овес), орзенин (рис) - и имеют гомологию последовательности аминокислот [16, 17]. Широко описаны аллергические реакции, возникающие при употреблении пшеницы [18, 19]. В Японии было показано, что среди пищевых аллергенов пшеница является наиболее частой причиной развития аллергических реакций [20]. В исследовании, проведенном E. Varjonen, было показано, что 97\% детей с атопическим дерматитом имели положительные результаты кожных тестов с пшеницей, 52,9\% - с овсом, 47,1\% - с рисом [21]. При этом диагностически значимый уровень $\mathrm{IgE}$ был обнаружен в 94,1 и 88,2\%, соответственно. А в работе J. Kwon пшеница как сенсибилизирующий агент играла роль для 18-25\% детей с атопическим дерматитом в зависимости от возраста [5]. Вместе с тем, по нашим данным, распространенность IgE-позитивного ответа на злаки значимо увеличивается с возрастом пациентов, но не превышает $35 \%$ среди пациентов с пищевой аллергией. Таким образом, наши данные, согласуясь с результатами, описанными в литературе, показывают высокую значимость аллергенов злаков в структуре сенсибилизации пациентов, начиная с грудного возраста.

Для детей старше 7 мес значимым триггером развития IgE-ответа становятся аллергены банана, частота IgEпозитивного ответа на который увеличивается с возрастом. Сходные данные отражены в работе M. Grob [22]. Сенсибилизация к аллергенам банана может наблюдаться в том числе и при бронхиальной астме. По данным исследований R. Kumar [23] и S.R. Agarkhedkar [24], частота сенсибилизации к банану колеблется от 1 до $83 \%$, а, по данным исследования T. Imamura [25], также может обусловливать развитие жизнеугрожающих состояний (у $2,8 \%$ детей).

По нашим данным, распространенность позитивной реакции при тестировании с аллергенами томатов возрастает у детей с пищевой аллергией в течение жизни, а для детей старше 10 лет становится сопоставимой с распространенностью IgE-позитивного ответа на аллергены банана. Появление с возрастом у детей значимого уровня IgE к аллергенам томатов можно объяснить возможностью перекрестных реакций между аллергенами банана и другими пищевыми аллергенами растительного происхождения, а также латекса [26]. Кроме того, известно, что в банане содержится белок глюканаза (эндо-бета-1,3глюканаза), который играет роль в развитии перекрестной реактивности IgE у пациентов с синдромом латексфрукты, а также в перекрестных реакциях с аллергенами томатов и картофеля [27], что объясняет тесную взаимосвязь роста числа IgE-позитивных ответов на данные аллергены с возрастом у пациентов с пищевой аллергией.

Смена ведущих триггерных факторов и рост числа позитивных ответов на аллергены моркови и томатов у детей старше 4 лет могут быть объяснены высокой перекрестной реактивностью данных аллергенов [28], тесной взаимосвязью IgE-ответа на пищевые аллергены растительного происхождения и пыльцевые аллергены. В связи с расширением спектра сенсибилизации с возрастом [3], развития так называемого атопического марша после 4 лет у отдельных пациентов с атопическим дерматитом развиваются также симптомы ингаляционной аллергии, одним из ведущих 
факторов которой является пыльца деревьев семейства Березовые. Тесная взаимосвязь антительного ответа на аллергены банана, томатов, тыквы в ряде случаев может быть связана с сенсибилизацией пациента к белку Bet v2 (в случае сопутствующей ингаляционной аллергии у пациента) [29]. В связи с этим ассоциация позитивного ответа на данные аллергены рассматривается авторами исследования как маркер сенсибилизации пациента к профилину березы [29]. Ведущая роль аллергенов моркови и томатов как сенсибилизирующих агентов среди аллергенов овощей указывается и в работе B.K. Ballmer-Weber, где также подтверждается тесная взаимосвязь появления сенсибилизации к рассматриваемым пищевым аллергенам с развитием у пациентов ингаляционной аллергии, ассоциированной с пыльцой березы [30].

Анализ антительного ответа на исследуемые пищевые аллергены животного происхождения у детей с пищевой аллергией показал наибольшую значимость в первом полугодии жизни аллергенов свинины, в возрасте 6-18 мес - говядины и свинины, а для детей старше 10 лет - говядины. Тенденции, полученные нами в отношении аллергенов говядины и свинины, подтверждаются работой J. Kwon, посвященной изучению влияния различных пищевых аллергенов, в том числе животного происхождения, на развитие атопического дерматита у детей различных возрастных групп [5]. J. Kwon показал, что среди рассматриваемых аллергенов - говядина, свинина, курица - частота позитивного ответа на свинину была максимальной у детей на первом году жизни. Вместе с тем указывается значительно большее число пациентов, у которых диагностически значимым фактором развития аллергии является курица и свинина. Низкая частота позитивного ответа на аллергены курицы и индейки при in vitro-тестировании, полученная в нашем исследовании, может быть объяснена тем, что мясо курицы как сильный сенсибилизирующий агент давно описан в литературе, а также хорошо изучены перекрестные аллергические реакции между курицей и индейкой. В связи с этим большинство пациентов, принявших участие в нашем исследовании, а также кормящие матери в профилактических целях исключали из своего рациона продукты из куриного мяса.

Выявленные закономерности изменения антительного ответа на различные пищевые аллергены в зависимости от возраста пациентов позволили нам определить наиболее актуальные диагностические панели для рассмотренных возрастных диапазонов и таким образом оптимизировать лабораторную диагностику. Данный подход особенно актуален для пациентов младше 3 лет, для которых невозможно выполнить кожные пробы, а также ограничен объем крови для проведения in vitroтестирования. Для таких пациентов требуется проведение исследования с наиболее частыми триггерами образования $\operatorname{IgE}$, а тестирование с аллергенами, значительно реже вызывающими образование IgE, целесообразно проводить в случае наличия убедительных анамнестических данных о том, что на них были аллергические реакции, или при неэффективности элиминационной диеты, назначенной с учетом результатов первого исследования. В то же время у пациентов старше 4 лет расширяется спектр значимых аллергенов, вызывающих образование специфических IgE: таким образом, диагностическая панель также требует расширения числа аллергенов.

\section{Заключение}

Спектр пищевой сенсибилизации у детей с ПА имеет возрастные отличия. Расширение с возрастом диапазона аллергенов, к которым организм сенсибилизирован, связано с введением в пищу новых аллергенов, а также с развитием перекрестных аллергических реакций. Набор пищевых продуктов, обладающих низкой аллергенной активностью, остается постоянным для детей разных возрастов. Наличие различных триггеров образования специфических IgE у детей с ПА разного возраста требуют различных диагностических подходов.

\section{Источник финансирования}

Работа выполнена при финансовой поддержке Министерства образования и науки Российской Федерации в рамках соглашения № 14.607.21.0017 о предоставлении субсидии (уникальный идентификатор прикладных научных исследований RFMEFI60714X0017).

\section{Конфликт интересов}

Авторы декларируют отсутствие явных и потенциальных конфликтов интересов, связанных с публикацией настоящей статьи.

\section{ЛИТЕРАТУРА}

1. Muraro A, Werfel T, Hoffmann-Sommergruber K, et al. EAACI food allergy and anaphylaxis guidelines: diagnosis and management of food allergy. J Allergy. 2014;69(8):1008-1025. doi: 10.1111/ all.12429.

2. Макарова С.Г., Намазова-Баранова Л.С., Вишнева Е.А. Актуальные вопросы диагностики пищевой аллергии в педиатрической практике // Вестник РАМН. - 2015. - №1. - С. 41-46. [Makarova SG, Namazova-Baranova LS, Vishneva EA. Topical issues of food allergy diagnosis in pediatric practice. Annals of the Russian Academy of Medical Sciences. 2015;70(1):41-46. (In Russ.)] doi: 10.15690/vramn.v70i1.1230.

3. Anto JM, Pinart M, Akdis M. Understanding the complexity of IgE related phenotypes from childhood to young adulthood: Mechanisms of the Development of Allergy (MeDALL) seminar. J Allergy Clin Immunol. 2012;129(4):943-954. doi: 10.1016/j.jaci.2012.01.047.

4. Bousquet J, Gern JE, Martinez FD, et al. Birth cohorts in asthma and allergic diseases: report of a NIAID/NHLBI/MeDALL joint workshop. J Allergy Clin Immunol. 2014;133(6):1535-1546. doi: 10.1016/j.jaci.2014.01.018.

5. Kwon J, Kim J, Cho S, et al. Characterization of food allergies in patients with atopic dermatitis. Nutr Res Pract. 2013;7(2):115-121. doi: $10.4162 / n r p .2013 .7 .2 .115$.

6. Rona RJ, Keil T, Summers C, et al. The prevalence of food allergy: a meta-analysis. J Allergy Clin Immunol. 2007;120(3):638646.

7. Venter C, Pereira B, Grundy J, et al. Incidence of parentally reported and clincally diagnosed food hypersensitivity in the first year of life. J Allergy Immunol. 2006;117(5):1118-1124.

8. Соснина О.Б., Балаболкин И.И., Ботвиньева В.В. Клинические и иммунные проявления пищевой аллергии у подростков // Российский педиатрический журнал. - 2008. - №3. - С. 14-17. [Sosnina OB, Balabolkin II, Botvin'eva VV. Clinical and immune manifestations of food allergy in adolescents. Rossiiskii pediatricheskii zhurnal. 2008;3:14-17. (In Russ.)] 
9. Балаболкин И.И. Пищевая аллергия у детей: современные аспекты патогенеза и подходы к терапии и профилактике // Иммунопатология, аллергология, инфектология. - 2013. №3. - C. 36-46. [Balabolkin II. Food allergy in children: modern aspects of pathogenesis and approaches to therapy and prophylaxis. Immunopatologiya, allergologiya, infektologiya. 2013;3:36-46. (In Russ.)]

10. Ito A, Ito $\mathrm{K}$, Morishita $\mathrm{M}$, et al. A banana allergic infant with $\mathrm{IgE}$ reactivity to avocado, but not to latex. Pediatr Int. 2006;48(3):321323. doi: 10.1111/j.1442-200x.2006.02211.x.

11. Moreno-Ancillo A, Dominguez-Noche C, Gil-Adrados AC, et al. Allergy to banana in a 5-month old infant. Pediatr Allergy Immunol. 2004;15(3):284-285. doi: 10.1111/j.1399-3038.2004.00162.x.

12. Prescott SL, King B, Strong TL. The value of perinatal immune responses in predicting allergic disease at 6 years of age. Allergy. 2003;58(11):1187-1194. doi: 10.1034/j.1398-9995.2003.00263.x.

13. Caruso B, Senna GE, Rizzotti P. Analysis of the positivity rate in IgE positive patients to food allergens in Verona Hospital laboratory during 2003. Eur Ann Allergy Clin Immunol. 2005;37(9):345-349.

14. Eriksson NE, Moller C, Werner S, et al. Self reported food hypersensitivity in Sweden, Denmark, Estonia, Lithuania, and Russia. $J$ Investig Allergol Clin Immunol. 2004;14(1):70-79.

15. Varjonen E, Vainio E, Kalimo K. Antigliadin IgE - indicator of wheat allergy in atopic dermatitis. Allergy. 2000;55(4):386-391. doi: 10.1034/j.1398-9995.2000.00451.x.

16. Battais F, Pineau F, Popineau Y. Food allergy to wheat: identification of immunoglobulin $\mathrm{E}$ and immunoglobulin G-binding proteins with sequential extracts and purified proteins from wheat flour. Clin Exp Allergy. 2003;33(7):962-970. doi: 10.1046/j.13652222.2003.01592.x.

17. Sievers S, Rawel HM, Ringel KP. Wheat protein recognition pattern in tolerant and allergic children. Pediatr Allergy Immunol. 2015. doi: 10.1111/pai.12502.

18. Rasanen L, Lehto M, et al. Allergy to ingested cereals in atopic children. Allergy. 1994;49(10):871-876. doi: 10.1111/j.1398-9995.1994. tb00790.x.

19. Sampson HA, Ho DG. Relationship between food specific IgE concentrations and the risk of positive food challenges in children and adolescents. J Allergy Clin Immunol. 1997; 100(4):444-451. doi: 10.1016/S0091-6749(97)70133-7.
20. Dohi M, Suko M, Sugiyama H, et al. Food-dependant exercise induced anaphylaxis; a study on 11 Japanese cases. J Allergy Clin Immunol. 1991;87(1 Pt.1):34-40.

21. Varjonen E, Vainio E, Kalimo K, et al. Skin prick test and RAST responses to cereals in children with atopic dermatitis. Characterization of IgE-binding components in wheat and oats by an immunoblotting method. Clin Exp Allergy. 1995;25:1100-1107. doi: 10.1111/j.1365-2222.1995.tb03257.x.

22. Grob M, Reindl J, Vieths S, et al. Heterogeneity of banana allergy: characterization of allergens in banana-allergic patients. Ann Allergy Asthma Immunol. 2002;89(5):513-516. doi: 10.1016/ S1081-1206(10)62090-X.

23. Kumar R, Singh BP, Srivastava P, et al. Relevance of serum IgE estimation in allergic bronchial asthma with special reference to food allergy. Asian Pac J Allergy Immunol. 2006;24(4):191-199.

24. Agarkhedkar SR, Bapat HB, Bapat BN. Avoidance of food allergens in childhood asthma. Indian Pediatr. 2005;42(4):362-366.

25. Imamura T, Kanagawa Y, Ebisawa M. A survey of patients with self-reported severe food allergies in Japan. Pediatr Allergy Immunol. 2008;19(3):270-274. doi: 10.1111/j.1399-3038.2007.00621.x.

26. Asero R, Mistrello G, Roncarolo D, et al. Detection of novel latex allergens associated with clinically relevant allergy to plant derived foods. J Allergy Clin Immunol. 2005;115(6):1312-1314. doi: 10.1016/j.jaci.2005.02.018.

27. Palomares $\mathrm{O}$, Villalba $\mathrm{M}$, Quiralte $\mathrm{J}$, et al. 1,3-beta glucanases as candidates in latex-pollen vegetable food cross-reactivity. Clin Exp Allergy. 2005;35(3):345-351.

28. Федорова О.С., Огородова Л.М., Солодовникова О.В. Пищевая аллергия у детей: аспекты эпидемиологии и естественного течения // Педиатрия. - 2009. - Т.87. - №2. - С. 120-125. [Fedorova OS, Ogorodova LM, Solodovnikova OV. Pishchevaya allergiya u detei: aspekty epidemiologii i estestvennogo techeniya. Pediatriya. 2009;87(2):120-125. (In Russ.)]

29. Asero R, Monsalve R, Barber D. Profilin sensitization detected in the office by skin prick test: a study of prevalence and clinical relevance of profilin as a plant food allergen. Clin Exp Allergy. 2008;38(6):1033-1037. doi: 10.1111/j.1365-2222.2008.02980.x.

30. Ballmer-Weber BK, Hoffmann-Sommergruber K. Molecular diagnosis of fruit and vegetable allergy. Curr Opin Allergy Clin Immunol. 2011;11(3):229-235. doi: 10.1097/ACI.0b013e3283464c74.

\section{КОНТАКТНАЯ ИНФОРМАЦИЯ}

Сновская Марина Андреевна, врач отдела инструментальной диагностики НИИ педиатрии ФГАУ «НЦЗД» Минздрава России Адрес: 119991, Москва, Ломоносовский пр-т, д. 2, стр. 1, тел.: +7 (495) 967-14-20, e-mail: snows@inbox.ru

Намазова-Баранова Лейла Сеймуровна, доктор медицинских наук, профессор, член-корреспондент РАН, директор НИИ педиатрии ФГАУ «НЦЗД» Минздрава России

Адрес: 119991, Москва, Ломоносовский пр-т, д. 2, стр. 1, тел.: +7 (495) 967-14-20, e-mail: namazova@nczd.ru

Семикина Елена Леонидовна, доктор медицинских наук, заведующая централизованной лабораторией лабораторного отдела ФГАУ «НЦЗД» Минздрава России

Адрес: 119991, Москва, Ломоносовский пр-т, д. 2, стр. 1, тел.: +7 (495) 967-14-20, e-mail: semikinaelena@yandex.ru

Макарова Светлана Геннадьевна, доктор медицинских наук, главный научный сотрудник отдела по клиническим исследованиям в педиатрии

Адрес: 119991, Москва, Ломоносовский пр-т, д. 2, стр. 1, тел.: +7 (495) 967-14-20, e-mail: sm27@yandex.ru

Кожевникова Ольга Викторовна, кандидат медицинских наук, заведующая отделом инструментальной диагностики НИИ педиатрии ФГАУ «НЦЗД» Минздрава России

Адрес: 119991, Москва, Ломоносовский пр-т, д. 2, стр. 1, тел.: +7 (495) 967-14-20, e-mail: fd@nczd.ru

Батырова Анна Сергеевна, врач отдела инструментальной диагностики НИИ педиатрии ФГАУ «НЦЗД» Минздрава России Адрес: 119991, Москва, Ломоносовский пр-т, д. 2, стр. 1, тел.: +7 (495) 967-14-20, e-mail: melograno8@yandex.ru

Марушина Анастасия Александровна, врач отдела инструментальной диагностики НИИ педиатрии ФГАУ «НЦЗД» Минздрава России

Адрес: 119991, Москва, Ломоносовский пр-т, д. 2, стр. 1, тел.: +7 (495) 967-14-20, e-mail: jasnoe@mail.ru 